\title{
Universidade de Classe Mundial no contexto Latino-Americano e Caribenho: o que dizem os Organismos Internacionais ${ }^{1}$
}

\section{World Class University in the Latin American and Caribbean context: what the International Organizations say}

\author{
Lara Carlette Thiengo* \\ Maria de Lourdes Pinto de Almeida* \\ Lucídio Bianchetti**
}

\begin{abstract}
RESUMO
Neste artigo se analisa o que dizem os Organismos Internacionais (OI) e seus especialistas acerca da possibilidade de construção e/ou existência de Universidades de Classe Mundial (UCM) nos países da América Latina e Caribe (ALeC), com o objetivo de evidenciar como estão sendo delineadas as especificidades deste modelo para esses países, que não compõem o eixo dinâmico do capital. Nesse mesmo sentido, buscou-se compreender o movimento desta tendência a partir dos lugares ocupados pelas universidades latino-americanas nos principais rankings acadêmicos internacionais. Em termos metodológicos, foram utilizados os levantamentos bibliográfico e de dados e a análise documental, considerando-se que a investigação sobre as tendências e manifestações da UCM pressupõe a compreensão da totalidade histórica e social.
\end{abstract}

Palavras-chave: Universidade de Classe Mundial. Universidade latinoamericana. Organismos Internacionais. Políticas de Educação Superior.

$1 \mathrm{O}$ artigo faz parte das elaborações desenvolvidas em Estágio de Pós-Doutorado, com financiamento da Capes.

* Universidade do Oeste de Santa Catarina. Programa de Pós-Graduação em Educação. Joaçaba, Santa Catarina, Brasil. E-mail: laracarlette@gmail.com. https://orcid.org/0000-0003-35934746. E-mail: malu04@gmail.com. https://orcid.org/0000-0001-8515-2908.

** Universidade Federal de Santa Catarina. Programa de Pós-Graduação em Educação. Florianópolis, Santa Catarina, Brasil. E-mail: lucidiob@gmail.com. https://orcid.org/0000-0003$2850-4692$. 


\begin{abstract}
In this article we analyze what International Organizations and their experts say about the possibility of building and/or existence of the World Class Universities in Latin America and the Caribbean countries, with the objective of highlighting how the specificities of this model for those countries, that do not make up the dynamic axis of capital, are being outlined. Regarding this, we seek to understand the movement of this tendency from the places occupied by Latin American universities in the main international academic rankings. In methodological terms, bibliographical data and documentary analysis are used, considering that the research on the trends and manifestations of the World Class Universities presupposes the understanding of the historical and social totality.
\end{abstract}

Keywords: World-Class University. Latin American University. International Organizations. Higher Education Policies.

\title{
Introdução
}

As expressões World Class University/Universidade de Classe Mundial (UCM) e Universidade de Excelência nos remetem constantemente às universidades que ocupam as primeiras posições nos rankings acadêmicos internacionais, uma vez que, há pouco mais de uma década, estes rankings vêm adquirindo expressiva notoriedade no que se refere à determinação/avaliação/inspeção da 'excelência' das Instituições de Educação Superior (IES) em todo o mundo (HALZENKORN, 2013). Do mesmo modo, a associação destas IES aos países que compõem o eixo dinâmico do capital, especialmente os Estados Unidos e a Inglaterra, corrobora o entendimento de ser este um modelo de universidade pouco provável/viável em países e regiões consideradas menos desenvolvidas, como, por exemplo, aquelas da América Latina e Caribe (ALeC).

Apesar de iniciarmos este texto com 'especulações' sobre o imaginário coletivo acerca destes termos e do modelo de universidade que representam, constatamos (THIENGO, 2018) que o modelo de UCM vem sendo apresentado pelos Organismos Internacionais (OI) desde a década de 2000 e é identificado a partir de um conjunto de características ou (pré) condições, tais como: i) uma alta concentração de talentos (professores e alunos); ii) abundantes recursos, para oferecer um ambiente de aprendizado rico e propiciar condições para o desenvolvimento de pesquisa avançada; e iii) características favoráveis de governança que incentivem visão estratégica, inovação e flexibilidade, permitindo 
que as instituições tomem decisões e gerenciem recursos sem se sobrecarregarem com a burocracia (ALTBACH; SALMI, 2011; SALMI, 2009).

Assim, apesar de o modelo de UCM expressar articulação imediata apenas com os países considerados mais avançados em ternos de desenvolvimento capitalista, trabalhamos com o pressuposto de que vem sendo elaborado e difundido um consenso acerca da necessidade de cada país possuir uma UCM. Isto ocorre até mesmo com aqueles países que não possuem condições de compor os primeiros lugares nos rankings, mas, a despeito disto, contam com IES que se destacam em suas regiões, agrupamentos ou blocos, como ocorre em alguns países da ALeC.

Diante do exposto, analisamos neste artigo o que dizem os OIs - Banco Mundial (BM) e Organização das Nações Unidas para a Educação, a Ciência e a Cultura (Unesco) - e seus especialistas (experts) acerca da construção de UCM nos países da ALeC. Fazem parte do nosso corpus documental as seguintes publicações: New higher education paradigm: from institutional qualities to systemic excellence (SADLAK; CAI, 2009) e Universidad y desarrolho en Latino America: experiencias exitosas de centros de investigación (SCHAWARTZMAN, 2008), de autoria da Unesco, e El desafio de criar universidades de rango mundial (SALMI, 2009) e El camino hacia la excelencia académica: la constitución de Universidades de Investigación de Rango Mundial (ALTBACH; SALMI, 2011), de autoria do Banco Mundial (BM). A escolha destes documentos foi orientada por estes critérios: sua relevância para a discussão e difusão do tema no período 2000-2018; a presença de diagnósticos sobre instituições da $\mathrm{ALeC}$; e por apresentarem conteúdo relacionado ao debate das UCM nos "centros e periferias" (SADLAK, CAI, 2009).

Nesse mesmo sentido, buscamos compreender o movimento desta tendência a partir dos lugares ocupados pelas universidades latino-americanas nos principais rankings internacionais (Shangai Ranking, Thimes Higher Education $[T H E]$ e $Q s$ Ranking). Salientamos, pois, que a opção por utilizar dados oriundos destas tabelas classificatórias não expressa concordância com esta tecnologia de avaliação/governança, mas sim o reconhecimento de serem estas classificações objetos de análise e importantes fontes de dados. Para além disso, compreendemos que a perspectiva de classe mundial não está desarticulada do processo de emergência e proeminência dos rankings. Isto é, não estamos tratando de movimentos distintos, o que, outra vez, valida a utilização destes dados. Cabe ressaltar, contudo, que, apesar de incitarem todas as IES à constante competitividade internacional, os rankings colocam em desvantagem a grande maioria delas, como as latino-americanas, o que significa que esta 'corrida' não tem os mesmos pontos de chegada para todos os 'competidores' (MARGINSON, 2006). 
Para tratar desse particular, em termos metodológicos, lançamos mão dos levantamentos bibliográfico e de dados e da análise documental, orientando-nos pela compreensão das contradições, das mediações e da totalidade histórica. Isto é: "[...] apreender as determinações que constituem o núcleo fundamental de um fenômeno, sem o que esse fenômeno não se constituiria" (FRIGOTTO, 1991, p. 187).

\section{Universidade de Classe Mundial: aspiração para todos?}

Para compreender o modo com que as universidades latino-americanas e caribenhas figuram no discurso dos OIs no que diz respeito ao desenvolvimento de UCM, faz-se importante apreender de forma mais ampla a maneira com que este modelo de universidade é posto como possibilidade/horizonte para os países que não fazem parte do eixo dinâmico do capital.

De acordo com Altbach e Salmi (2011, p. 1), para além de participar da "Rede Global do Conhecimento", universidades centradas em pesquisa são consideradas peças-chave para o desenvolvimento econômico dos países de renda média e baixa. Inclusive, fazendo referência ao livro publicado por Altbach e Balán (2007), World Class Worldwide: transforming research universities in Asia and Latin America, os autores reconhecem a importância do papel das Universidades de Pesquisa em regiões de rápido crescimento, da Ásia e da América Latina.

Na publicação organizada pela Unesco (SADLAK; CAI, 2009), a diferença entre o potencial para alcançar a excelência é colocada de modo sutil, ao se sentenciar a impossibilidade de haver uma universidade de investigação de excelência em cada país, mas, ainda assim, ressalva-se que muitos países em desenvolvimento e de renda média podem desenvolver universidades com capacidade de pesquisa e detentoras de habilidades para participar do sistema de conhecimento mundial. Indica-se como alternativa para os países menores ou menos desenvolvidos "[...] a formação de alianças acadêmicas regionais, para construir a força suficiente em campos selecionados, a fim de promover a participação na ciência global"' (SADLAK; CAI, 2009, p. 66, tradução nossa). Ou seja, uma alusão à cooperação e à formação de redes como alternativa para os países periféricos desenvolverem-se de modo 'excelente'.

Um dos capítulos do referido documento produzido pela Unesco (SADLAK; CAI, 2009), inclusive, tem como objetivo discutir o papel das pequenas nações e suas universidades na economia global do conhecimento, bem como examinar alternativas estratégicas para os tomadores de decisão destes países se adaptarem 
aos rankings, uma vez que deve ser considerada "a incapacidade das pequenas nações e de suas universidades para competirem em condições de igualdade no recrutamento e na prestação continuada de recursos para atrair e desenvolver pesquisadores com altos índices de citação ou ganhadores de importantes prêmios" (SADLAK; CAI, 2009, p. 187, tradução nossa). Assim, tem-se que, “[...] na economia global, pequeno significa que você tem que ser focado e ágil, encontrar um nicho e trabalhar com parceiros" (SADLAK; CAI, 2009, p. 185, tradução nossa).

No documento de autoria do BM (SALMI, 2009) são apresentados gráficos para ilustrar as referidas relações entre o grau de desenvolvimento econômico e científico dos países e a presença de UCM (a partir dos resultados dos rankings), o que enfatiza a compreensão - que é convergente entre os OIs - de que as distinções entre os graus de desenvolvimento econômico e científico dos países 'influenciam' na forma como estes devem traçar suas estratégias para alcançar o status de classe mundial. Entretanto compreendemos que 'o horizonte' da excelência e a promoção da competitividade compõem, essencialmente, a 'mensagem' implícita em tais publicações.

\section{Horizonte de Classe Mundial para os países da América Latina e Caribe nos documentos do BM e Unesco}

Na publicação do BM assinada por Altbach e Salmi (2011) encontramos referência a algumas instituições latino-americanas e caribenhas que estariam se aproximando/buscando o status de classe mundial. Os capítulos apresentam análises de 'novas iniciativas' de promoção de UCM, como as promovidas pelas seguintes IES: Universidade de Jiao Tong de Shanghái, Universidade de Ciência e Tecnologia de Hong Kong, Universidade de Ciência e Tecnologia de Pohang, Universidade Nacional de Singapura, Institutos de Tecnologia Hindús e de Bombay, Universidade de Idabán, Universidade do Chile (UCH), Pontifícia Universidade Católica do Chile (PUC-Chile), Escola Superior de Economia Russa, entre outras.

A análise dessas instituições permite apresentação de diferentes estratégias que poderiam levar à consecução de Universidades de Excelência, ainda que as referidas instituições não possam ser consideradas de 'classe mundial', já que não correspondem aos "[...] estândares fixados pela maior parte das Universidades de Investigação Intensiva de Classe Mundial localizadas nos países desenvolvidos" (ALTBACH; SALMI, 2011, p. 304, tradução nossa). 
Interessam-nos, neste momento, considerando o escopo do artigo, os casos apresentados sobre os países latino-americanos: Chile (assinado por Andrés Bernasconi) e México (assinado por Francisco Marmolejo).

De acordo com a publicação, as duas melhores instituições do Chile, que também estão entre as melhores da ALeC, são: UCH e PUC-Chile, pública e privada, respectivamente. A justificativa apresentada pelo autor para o destaque dado a estas instituições reside em dois fatores principais, a saber: a presença de ambas as instituições nas primeiras colocações em rankings nacionais e regionais e por terem sido escolhidas pela grande maioria dos alunos detentores das maiores notas no exame nacional de ingresso na universidade. Para além destes indicativos de 'excelência', o autor aponta também questões relacionadas ao reconhecimento institucional e ao número de publicações indexadas, como vemos no trecho a seguir:

Juntas, essas duas universidades de vanguarda publicam mais da metade de todos os artigos indexados pelo ISI [Institute for Scientific Information] e gerados por pesquisadores chilenos, e a parcela dos recursos alocados sob o regime de concorrência para o desenvolvimento de processos de pesquisa, representa cerca de $60 \%$ do total atribuído a todo o sistema. Mais de $60 \%$ dos presidentes chilenos estudaram na UCH, e seus graduados, juntamente com os da PUC [Chile], incluem mais da metade dos melhores empresários e políticos do país (ALTBACH; SALMI, 2011, p. 278 , tradução nossa).

Sobre esta questão, há que se destacar o alto grau de seletividade no recrutamento de novos alunos para as referidas universidades, o que garante que as melhores universidades do país recebam os melhores alunos. No entanto, a avaliação acaba reproduzindo as diferenças na qualidade do ensino a que cada classe social tem acesso.

Cabe a ressalva que, em termos de financiamento, o sistema chileno é uma exceção na ALeC. Nesse sentido, de acordo com o documento (ALTBACH; SALMI, 2011, p. 278), os “[...] irrisórios fundos públicos recebidos pela UCH não são suficientes para uma universidade moderna", tampouco para uma UCM, que, como indica Salmi (2009), precisa atrair alto e diversificado financiamento. Considerando esta especificidade, a avaliação em relação ao trabalho feito por estas instituições, nesse contexto, é positiva. A PUC-Chile, por sua vez, sofre menos no que que tange ao financiamento, uma vez que, por ser privada/confessional, não está endividada, e suas obrigações financeiras são notadamente 
menores que as da UCH. Aliás, a PUC-Chile é considerada pelo autor "“[... uma das poucas universidades da $\mathrm{ALeC}[. .$.$] que lograram êxito comprometendo-se$ com o desenvolvimento do seu perfil de pesquisa" (ALTBACH; SALMI, 2011, p. 308, tradução nossa).

De acordo com Salmi (2013), embora o Estado chileno tenha aumentado sua contribuição financeira para o ensino superior nos últimos anos, expressiva proporção dos recursos foi destinada a bolsas de estudo e empréstimos educacionais. Para o autor, isso é importante para eliminar as barreiras econômicas ao acesso, mas não contribui diretamente para que as universidades desenvolvam suas atividades de pesquisa. Ou seja: as universidades chilenas não têm o mesmo nível de recursos para competir com as melhores universidades de outros países da Organização para a Cooperação e Desenvolvimento Econômico (OCDE).

Outro problema apontado pela publicação (ALTBACH; SALMI, 2011) está relacionado ao fato de estas instituições não terem como foco central a pesquisa, isto é: UCH e PUC-Chile ainda possuem como principal função a formação no âmbito da licenciatura, com baixa matrícula de pós-graduação. Assim como indica Salmi (2013), o número e o nível de doutorados das universidades chilenas está muito abaixo do nível das universidades dos países "industriais".

No que se refere à internacionalização, o nível do Chile é considerado baixo em relação à média da $\mathrm{OCDE}$, o que é tido como um fator limitante na busca pela 'excelência', uma vez que tem implicações para a mobilidade dos estudantes chilenos. De acordo com Salmi (2013), a baixa internacionalização também impede que se imprima o mesmo grau de seletividade na admissão em programas de pós-graduação de outros países, devido à forte competição entre estudantes nacionais e internacionais.

Sob essa ótica, uma forma eficaz de melhorar o nível acadêmico seria a atração de destacados pesquisadores de outros países (ou chilenos que trabalham em universidades estrangeiras), o que só se tornaria viável se salários competitivos puderem ser oferecidos internacionalmente.

Em suma, de acordo com Salmi (2013, p. 30), para alcançar o nível de Classe Mundial, o Chile precisa que autoridades nacionais e líderes de universidades se adaptem

[...] à missão de cumprir o papel cada vez mais importante da educação superior no desenvolvimento econômico do Chile e estar atentos não apenas aos avanços do sistema brasileiro de pós-graduação e pesquisa mas também ao impressionante progresso das jovens universidades do leste da Ásia. Enfrentar esta competição regional e internacional de maneira bem-sucedida requer o desenvolvimento de uma visão clara de 
longo prazo, definindo e tomando o conjunto de reformas e medidas e comprometendo-se com o investimento financeiro que deve acompanhar essas medidas de longo prazo. Tendo cumprido todas essas condições, o Chile pode realizar o sonho de ter Universidades de Classe Mundial e alcançar os níveis de desempenho acadêmico e científico a que o país aspira legitimamente (tradução nossa).

Assim, como assinalamos anteriormente, a publicação também faz menção ao caso do México, país em que "[...] a paisagem do ensino superior [...] mudou rapidamente nos últimos anos, em termos de dimensão, complexidade e diversificação" (ALTBACH; SALMI, 2011, p. 317). Dados indicam que:

Em 2008, todo o sistema nacional compreendia 2.442 instituições de ensino superior, das quais 843 eram públicas e as 1.599 restantes eram privadas. Nessas instituições, foram treinados 2.814 .871 alunos, dos quais $65,7 \%$ estavam matriculados em instituições públicas e 34,3\% estavam matriculados em universidades privadas (Tuirán, 2008). O crescimento do sistema é impressionante se considerarmos que 60 anos antes a matrícula nacional no ensino superior representava cerca de 30 mil estudantes em algumas instituições, incluindo o ITESM [Instituto Tecnológico e de Estudos Superiores de Monterrey], que treinou apenas cerca de 200 alunos (ALTBACH; SALMI, 2011, p. 317, tradução nossa).

De acordo com a publicação, a Universidade Nacional Autônoma do México (Unam) e o Itesm têm desenvolvido projetos que almejam transformá-los em Universidades de Excelência. Todavia, a análise do capítulo em questão dá ênfase ao ITESM, sob a justificativa de haver um grande número de trabalhos sobre a Unam.

O Itesm é composto por um conjunto de campi que possuem características bastante distintas entre si, especialmente no que se refere ao tamanho e à infraestrutura, uma vez que há poucos campi grandes e muitos pequenos ${ }^{2}$. De acordo com a publicação, tais características são um empecilho para o alcance

2 Uma informação interessante sobre o Itesm diz respeito à realização de três edições de uma Loteria Nacional, que gera recursos para concessão de bolsas de estudo e, mais recentemente, para o financiamento de novas cadeiras, que foram convertidas em sistemas-chave para apoiar a atividade de pesquisa da universidade. 
da excelência na área de pesquisa, o que coloca a necessidade de desenvolver estratégias de estratificação interinstitucional. Para além disso, também são dirigidas críticas à gestão da instituição. Afirma-se que é "“[...] muito difícil para pequenos campi poderem se comprometer com a pesquisa, enquanto campi maiores podem considerar essa aspiração mais legítima, adequada e alcançável" (ALTBACH; SALMI, 2011, p. 327, tradução nossa).

Em resposta a esta problemática, os gestores da referida instituição decidiram dar enfoque a algumas áreas a partir da criação de vários centros de investigação a ela vinculados, para identificar as necessidades e os nichos de mercado em âmbito local, os quais podem ser assistidos pela capacidade de investigação do Itesm. As áreas selecionadas foram: Biotecnologia e Nutrição; Medicina; Indústria e Design; Mecatrônica, Nanotecnologia, Tecnologia da informação e Telecomunicações; Desenvolvimento Sustentável; Administração de Empresas; Ciências Sociais; Humanidades; Desenvolvimento Regional; Desenvolvimento Social; e Pedagogia. Sobre esta estratégia, a análise de Marmolejo no documento em questão indica que podem haver implicações positivas e negativas: “[...] por um lado, ajuda a instituição a concentrar seus recursos e por outro limita a criatividade e a inovação das outras áreas" (ALTBACH; SALMI, 2011, p. 21).

Uma das estratégias adotada pela instituição e apresentada como eficaz é a concessão de apoio financeiro aos pesquisadores que desenvolvem suas pesquisas nas áreas prioritárias elencadas acima, por meio do Programa de Dotación de Cátedra $^{3}$. Ainda assim, tais recursos financeiros são significativamente inferiores aos de Programas similares desenvolvidos em Universidades de Classe Mundial. Essa estratégia de pesquisa é complementada ainda por um programa paralelo, que busca conectar o Itesm de forma mais efetiva ao setor empresarial e também tem concentrado esforços na construção de centros de incubação ou promoção de empresas, bem como em centros tecnológicos.

Outra característica desta instituição alinhada à perspectiva de classe mundial é a presença de uma abordagem global em sua estratégia internacional, o que ajudou substancialmente a melhorar sua reputação internacional como "instituição comprometida com a internacionalização", o que se verifica pelo fato de que "[...] muitas estratégias projetadas por especialistas internacionais estão presentes no Itesm" (ALTBACH; SALMI, 2011, p. 339). Algumas dessas estratégias são: inclusão de uma dimensão internacional no currículo de

3 Cada cátedra é aprovada por um comitê especial, com base em uma proposta feita por uma equipe de pesquisadores. Uma vez aprovada, o presidente recebe financiamento por cinco anos, no valor total de US\$ 150 mil, e, durante esse período, fundos externos adicionais devem ser arrecadados por um valor similar ou maior do que o contribuído. 
todos os programas acadêmicos; recrutamento de estudantes e de acadêmicos internacionais; envio de um grande número de estudantes e de acadêmicos ao exterior; oferta de opções de grau duplo para os alunos; desenvolvimento de grupos de pesquisa internacionais; desenvolvimento de processos de pesquisa com uma dimensão internacional; estabelecimento de mais de 400 acordos sobre memorandos internacionais e manutenção de escritórios de representação em muitos países.

Ainda sobre a internacionalização, cabe mencionar que o Itesm $^{4}$ foi o primeiro Instituto não norte-americano credenciado por uma agência de acreditação dos EUA. Desse modo, a conquista de um selo de garantia de qualidade internacional contribuiu de forma importante para elevar a qualidade e aumentar o prestígio dessas duas universidades (Itesm e Unam) localizadas na América Latina.

Contudo, uma das preocupações dos autores com este quesito diz respeito ao fato de que essa abordagem, “[...] embora bem-sucedida quando se trata de manter o desenvolvimento da instituição, pode não ser suficiente para enfrentar os níveis de investimento em infraestrutura para pesquisa, que são necessários para sustentar o status da Universidade de Pesquisa no ranking mundial" (ALTBACH; SALMI, 2011, p. 342, tradução nossa).

Na publicação do BM El desafio de crear universidades de rango mundial (SALMI, 2009), a Universidade de São Paulo (USP) é mencionada, ainda que não se trate de um estudo de caso sobre a instituição. A referida IES é citada como um exemplo para o argumento de que a criação de uma UCM não está relacionada apenas aos recursos, apesar de eles serem uma questão muito relevante. De acordo com Salmi (2009), a USP pode ser considerada a universidade mais rica do Brasil. Todavia, as rígidas normas da administração pública e também o “[...] espírito de democracia tem se traduzido em múltiplos órgãos representativos (assembleias), o que complica a tomada de decisões e de qualquer forma de visão de futuro" (DURHAM, 2008 apud SALMI, 2009, p. 48).

Outro problema é a endogenia. Para o autor, esta instituição tem poucos vínculos com a comunidade internacional e está "muito centrada em si mesma", de modo que até mesmo a maioria dos docentes são graduados na mesma

4 É importante também destacar que esta instituição (Itesm) pode ser considerada de elite, visto que suas taxas/mensalidades são notadamente altas, e apenas uma pequena parte das famílias mexicanas pode pagar. Nesse sentido, uma das especificidades do Itesm em relação a instituições de outros países que buscam o status de classe mundial é o seu financiamento, já que o desenvolvimento do Itesm foi financiado na maior parte, cobrando altas taxas dos seus alunos, confiando nas contribuições dos seus doadores e na gestão lucrativa, enquanto a maioria das instituições com esse perfil é apoiada por um forte compromisso público. 
IES e também os seus estudantes são da região de São Paulo. A falta de visão estratégica é avaliada então como o principal problema. $\mathrm{O}$ autor ainda enfatiza:

O Brasil é a quinta nação do mundo na quantidade de população e a décima potência na economia, está entre os seis maiores produtores de automóveis do mundo, tem empresas de classe mundial, como Embraer e Aracruz Celulose e, no entanto, não há uma universidade entre as 100 universidades com melhor classificação do mundo. (SALMI, 2009, p. 48, tradução nossa).

Apesar de passada quase uma década da publicação deste texto e de alguns dados não mais expressarem da forma fidedigna a realidade, é inconteste o fato de que o Brasil ainda não possui nenhuma instituição no Top 100, apesar de algumas delas, como a USP, estarem promovendo esforços e mudanças para alcançar o status de UCM.

Por fim, Salmi (2009) afirma que as universidades latino-americanas não estão ranqueadas entre as melhores universidades do mundo devido ao tamanho das instituições (consideradas grandes, como nos casos do Brasil e da Argentina).

De modo convergente, na publicação da Unesco Universidade y desarrolho na America Latina (SCHWARTZMAN, 2008), tal questão também é mencionada uma vez que explicaria por que essas universidades (Universidad de Buenos Aires - UBA, Unam e USP) não conseguiram entrar na liga principal, apesar de abrigarem excelentes departamentos e centros de pesquisa que são, sem dúvida, de classe mundial.

Os estudos de caso, nesta publicação, são direcionados para Centros de Pesquisa de áreas estratégicas, e não para universidades, de modo a reforçar o problema relacionado ao alto número de alunos e também à necessidade de diferenciação inter e intrainstitucional. Tais Centros estavam localizados na Argentina, no Brasil, no Chile e no México.

A falta de professores com dedicação exclusiva (tempo integral) também é apontada como um indicativo problemático das universidades latino-americanas e caribenhas, já que, em muitos casos, os professores precisam atuar em outras frentes para completar sua renda (consultorias, trabalhar em outras universidades etc.). Outra crítica ao quadro docente se refere ao pouco esforço das universidades deste subcontinente em atrair talentos de outros países, problema relacionado à remuneração, à ausência de políticas de internacionalização que visem à atração de docentes e discentes, à oferta de cursos na língua inglesa, entre outras. 
De modo geral, nas publicações da Unesco e do BM, a análise de casos e da promoção iniciativas de excelência são predominantes enquanto estratégia discursiva para apresentar 'lições', 'comparações' e 'problemas'. Assim, as publicações são constituídas por um conjunto de capítulos, assinados por diferentes intelectuais, de várias regiões do globo.

Todavia, a utilização recorrente de exemplos/casos dessa natureza pode ser compreendida como uma estratégia discursiva que, ao narrar, dissemina novas ideias, naturaliza relações, compara e 'ensina'. Nos documentos analisados, apesar de estas instituições serem apresentadas como uma espécie de casos de 'sucesso', no que se refere à possibilidade de existirem potenciais UCM em países que não compõe o eixo dinâmico do capital, o discurso trazido por estes documentos dá maior ênfase aos problemas considerados pelos autores como 'entraves' ao melhor desenvolvimento dessas universidades rumo ao status de Classe Mundial. Esse 'núcleo problemático' apresentado pelos autores concentrou-se: 1) no tamanho das instituições; 2) no fato de que não são suficientemente centradas em pesquisa; 3) no fato de as áreas estratégicas não estarem sendo devidamente priorizadas; 4) no fato de a burocracia ser um entrave para o desenvolvimento dessas instituições; 5) e no baixo nível de internacionalização.

Por outro lado, as referidas publicações também buscam identificar 'fatores de aceleração' que poderiam contribuir positivamente com a busca por excelência. O primeiro deles diz respeito ao uso extensivo da diáspora na tentativa de criar uma nova universidade ou de melhorar uma instituição existente. O segundo fator é o uso da língua inglesa como a principal língua de ensino e pesquisa, o que permite atrair estudantes e acadêmicos estrangeiros altamente qualificados. A terceira forma é focar em programas em áreas estratégicas para o país, como disciplinas de ciência e engenharia, que permitem que uma massa crítica seja alcançada mais rapidamente. O quarto caminho é baseado em um processo de benchmarking, a fim de orientar os esforços de melhoria das instituições. O quinto fator tem a ver com as inovações curriculares e pedagógicas introduzidas por essas universidades. (SALMI, 2013).

Outro argumento importante trazido por essas publicações está baseado na compreensão de que os governos estão cada vez mais 'conscientes' da importância e da contribuição do alto desempenho das UCM para a competitividade global e o crescimento econômico, ou seja, da necessidade de conferir a uma ou mais universidades o status 'de elite', para que possam competir efetivamente com as melhores do mundo, bem como compor vantajosamente os rankings internacionais.

Tendo-se em vista o exposto, é importante destacar que a representação da realidade trazida pelos documentos dos OIs exprime juízos de valor (a partir da perspectiva liberal) como se fossem juízos de fato, ou verdades (FAIRCLOUGH, 2001). Desse modo, entendemos que as afirmações que corroboram essa tese 
neoconservadora estão alicerçadas na interpretação da política monetária como uma questão estritamente técnica, descolada do projeto político-econômico capitalista e do modus operandi da legitimação dos privilégios.

Nesse sentido, entendemos que se sobressai a determinação econômica do projeto de UCM, bem como o discurso meritocrático, no que se refere ao acesso dos estudantes e às possibilidades de criação deste modelo de instituição nos diferentes países. A naturalização dessa vinculação, contudo, não revela as características da relação capital-trabalho que subjazem a um projeto histórico da classe dominante, o qual, muitas vezes, é apresentado de forma sutil, com uma linguagem rebuscada, respaldado por uma série de dados, diagnósticos e rankings.

Especificamente os rankings merecem especial atenção, uma vez que são evocados como argumento para uma série de questões: a escolha das IES a serem analisadas; a pouca expressividade desses países nos rankings; a dificuldade para que essas instituições alcancem posições mais elevadas nos rankings; os países que concentram o maior número de universidades pertencente ao 'topo' da lista, entre outras. Há, como indica Fairclough (2001), uma relação entre textos (intertextualidade), com o objetivo de afirmar/justificar dado argumento ou escolha. Do mesmo modo, também se reforça o poder legitimador dos rankings no tratamento da medida da qualidade da educação superior.

Os rankings, nesse caso, podem ser considerados tecnologias de performatividade (BALL, 2005), na medida em que, claramente, são produzidos e divulgados a partir do julgamento e da comparação, bem como contribuem para reforçar/produzir a cultura da competitividade no âmbito da mercadorização da educação. Para Ball (2005, p. 40), "as performances objetivam, por um lado, a construção cultural, a instilação do orgulho, a identificação e/ou crença”. De outro lado, avaliações e classificações, postas no âmbito da competição entre grupos internos às instituições, podem engendrar sentimentos individuais de orgulho, de culpa, de vergonha e de inveja. Isso significa que as tecnologias de performatividade, juntamente com o gerencialismo, reformulam não apenas as relações mas também as subjetividades dos envolvidos no processo educacional, o que em muito nos ajuda a compreender as motivações dos países e das instituições da $\mathrm{ALeC}$ na corrida pela 'excelência'.

Entendemos, em razão do crescimento do número de instituições ranqueadas e também das posições alcançadas pelas universidades latino-americanas e caribenhas nos rankings internacionais ao longo da última década, que a corrida pelo status de classe mundial vem ganhando materialidade também nestes países, como veremos no item seguinte. 


\section{Universidades da ALeC nos rankings}

Como viemos tratando ao longo deste artigo, entendemos que necessidade de 'correr' e se adequar às exigências da competição, portanto, está articulada à difusão de um consenso sobre a 'excelência', haurido do modelo de UCM, o que, por sua vez, não está desarticulado de um movimento mais amplo de transformações da universidade no âmbito da proclamada 'globalização' e da mundialização do capital (CHESNAIS, 1996).

Nesse sentido, é importante considerar um conjunto de transformações que o cenário da educação superior na ALeC tem sofrido ao longo das últimas três décadas, a saber: observa-se uma significativa ampliação da taxa de matrícula nesses países $^{5}$; maior diversificação institucional; incremento da participação do setor privado na prestação dos serviços educacionais, incluindo a oferta transnacional; a redução progressiva do investimento público no setor, sendo as universidades públicas cada vez mais impelidas a buscar novas fontes de financiamento ${ }^{6}$.

De acordo com dados da Unesco (2015), Brasil, México e Argentina são os países que possuem os maiores sistemas de educação superior na região ${ }^{7}$. Venezuela, Colômbia, Peru, Chile e Cuba possuem entre 800 mil e dois milhões de matrículas, aproximadamente, e podem ser considerados medianos. Contudo, o tamanho dos sistemas não se relaciona proporcionalmente com a capacidade de atendimento de cada Estado-nação. Se considerarmos a taxa bruta de matrícula, o Chile e a Argentina, com respectivamente $87 \%$ e $80 \%$, são os países que apresentam a melhor razão entre o número total de estudantes e a população correspondente na faixa etária prevista (18-24 anos). Brasil e Chile também estão entre os países com maior expansão do setor privado, chegando a mais de $70 \%$ no Brasil e a cerca de $80 \%$ no Chile ${ }^{8}$. Em direção oposta, estão

5 Com base em dados do Instituto de Estatística da Unesco (2016), de 13 milhões de estudantes na educação superior na década de 1960, avançou-se para cerca de 198 milhões de matrículas no ano de 2013, no mundo todo. Enquanto a ALeC passou de cerca de 1,5 milhão para quase 21 milhões de estudantes de nível terciário no mesmo intervalo.

6 Tais transformações, como indicamos anteriormente, não estão 'soltas' no espaço e no tempo, mas sim articuladas à dinâmica do capitalismo - à mundialização do capital; nesta mesma lógica também as transformações do Estado, com o avanço do neoliberalismo e a culminância de novas formas de gerir o social em escala global.

7 O Brasil concentra mais de sete milhões de matrículas; México e Argentina possuem entre dois e três milhões de estudantes.

8 Neste caso, é uma distinção importante: as instituições privadas que operam no sistema brasileiro têm caráter não universitário; no Chile, embora o ensino seja pago, é ofertado majoritariamente por instituições universitárias de origem estatal. 
Uruguai, Bolívia, Argentina e Panamá, onde a participação do setor privado é inferior a 30\% (UNESCO, 2015).

Brasil, Chile, Argentina e México também são os países que possuem o maior número de universidades ranqueadas a cada ano. Além disso, as IES destes países apresentam as melhores posições, em comparação com as demais IES latino-americanas.

Nesse sentido, podemos observar o crescimento do número de IES latinoamericanas ranqueadas ao longo desta década nos três principais rankings acadêmicos internacionais: Shangai Ranking, THE e Qs Ranking ${ }^{9}$. Nos gráficos 1,2 e 3 é possível visualizar esse movimento:

\section{GRÁFICO 1 - NÚMERO DE IES DA ALEC RANQUEADAS PELO SHANGAI RANKING NO PERÍODO 2010-2018}

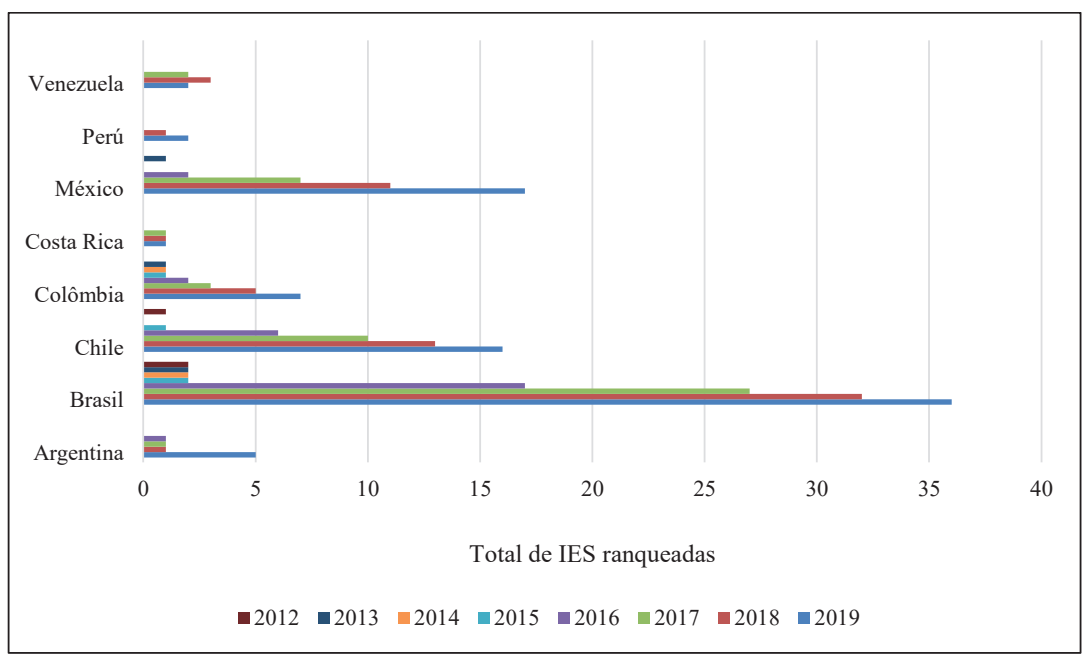

FONTE: Elaborado pelos autores com base no site do Shangai Ranking.

9 Ainda que consideremos as diferenças entre as métricas dos referidos rankings e algumas mudanças no que se refere aos critérios destes ao longo dos anos (inclusive a ampliação do número total de universidades ranqueadas). 
GRÁFICO 2 - NÚMERO DE IES DA ALEC RANQUEADAS PELO THE NO PERÍODO 2010-2018

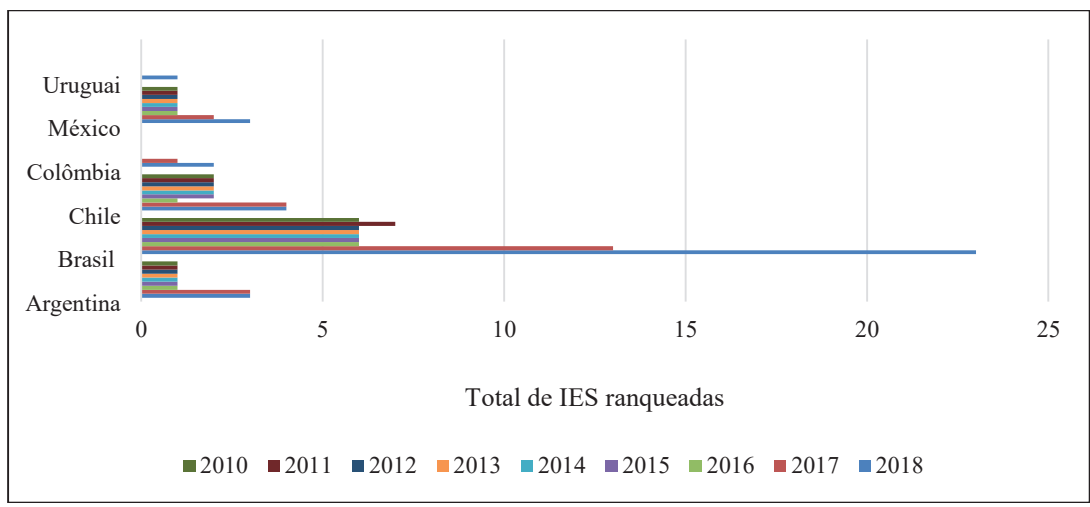

FONTE: Elaborado pelos autores com base nas classificações dos rankings.

GRÁFICO 3 - NÚMERO DE IES DA ALEC RANQUEADAS PELO QS WORLD UNIVERSITY RANKINGS NO PERÍODO 2016-2019

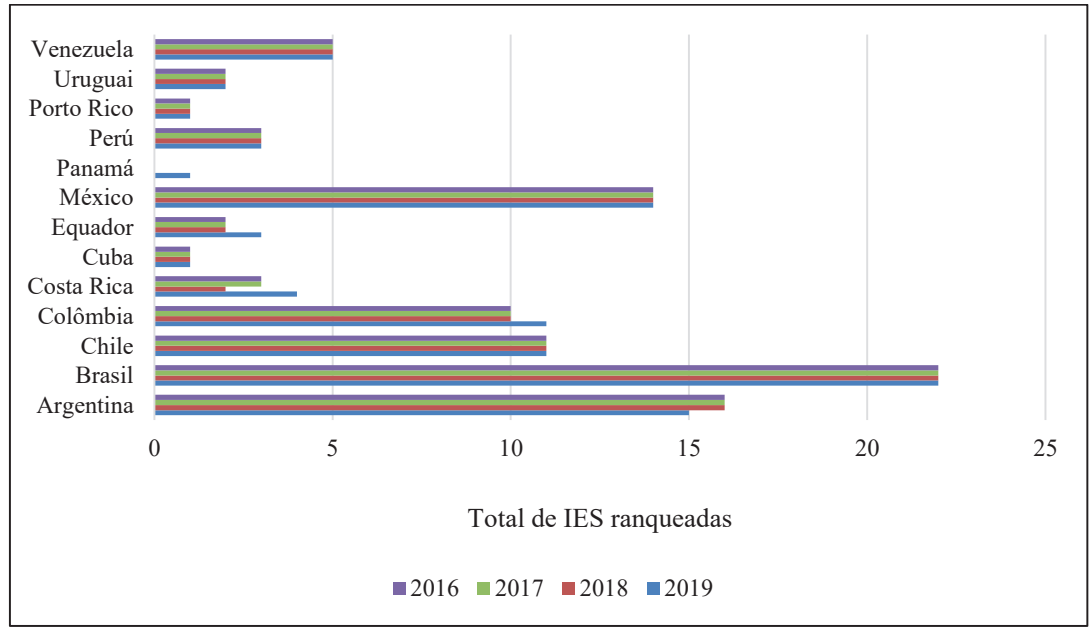

FONTE: Elaborado pelos autores com base nas classificações do QS Ranking.

10 Os dados mais antigos disponibilizados no site do ranking QS são de 2016. 
Até mesmo países que não possuíam universidades ranqueadas passaram a compor alguma das listas, ainda que, em geral, em posições fora do Top 400, como é o caso do Panamá, que aparece na lista do QS 2019. Costa Rica passou a ter uma universidade representante no ranking $Q S$ a partir de 2016 e nos dois outros rankings a partir de 2017. Uruguai passou a compor a lista do $Q S$ em 2016 e a do THE em 2018. Venezuela também foi incluída no Ranking de Shangai em 2017 e no $Q S$ a partir de 2016.

As universidades que se destacaram ao longo dos anos nos diferentes rankings são: USP, Universidade Estadual de Campinas (Unicamp) e Universidade Federal do Rio de Janeiro (UFRJ), no Brasil; PUC-Chile e UCH, no Chile; Unam e Itesm, no México; UBA, na Argentina; e Universidade dos Andes, na Colômbia.

Um dado curioso é que nem todas as universidades da ALeC que alcançam boas classificações nos rankings foram analisadas/apresentadas nos documentos dos OIs. Por exemplo, a UBA, por exemplo, não é citada. Também a USP, que em geral ocupa boa classificação nos rankings, apesar de citada (SALMI, 2009), não foi analisada em capítulos específicos, como no caso das universidades do Chile e do México. Já em comparação com os demais países analisados, há maior recorrência de países europeus, norte-americanos e asiáticos.

De modo geral, é relevante considerar que a criação de rankings regionais ou a publicação dos resultados por região podem ser consideradas formas de inclusão, ainda que à margem, dos países considerados menos desenvolvidos. Sendo assim, uma análise desse movimento mais atual, conquanto limitada, permite-se supor que o modelo/concepção de UCM serve para reforçar a lógica de privatização das universidades e de justificativa para a necessidade de priorização dos recursos para as IES que podem assumir o posto de vanguarda científica nacional.

\section{Considerações finais}

Por ora, concluímos que, apesar de as universidades consideradas de excelência ou classe mundial se limitarem a um grupo muito pequeno de instituições que procuram estar no topo dos sistemas nacionais e internacionais de educação, esse número vem crescendo nos últimos anos, em decorrência da maior expressividade que este modelo ou status de universidade passou a adquirir no cenário global. No caso dos países da $\mathrm{ALeC}$, percebemos maior participação de algumas IES desses países nos rankings internacionais, bem como maior destaque a um grupo de instituições, o que pode ser considerado um indicativo de que o modelo de UCM vem ganhando notoriedade na sub-região. 
Importa considerar que não se trata de coincidência ou de simples alinhamento de ordem modernizadora, mas sim de um movimento que ocorre porque a expansão e consolidação do capitalismo exige a internacionalização das políticas públicas, das regras e normas dos sistemas de gestão, produção, financiamento e consumo em todo o território a que as IES atendem.

Isso é possível porque a mundialização do capital permitiu ao capitalismo expandir fronteiras e unir agregados nacionais e continentais, constituindo assim relações de interdependência e aproximando seus métodos econômicos, formas sociais e níveis de desenvolvimento. Essas sobreposições dialéticas entre inovações tecnológicas, políticas e culturais produzidas pelos países avançados e as relações sociais nos ambientes 'atrasados' exprimem a essência desigual e combinada do desenvolvimento capitalista realizado pelos países retardatários (BIANCHI, 2013). Esse processo ocorre geralmente pela assimilação dos elementos mais modernos das nações avançadas e por sua adaptação a condições materiais e culturais menos avançadas, uma vez que o capital, em seu estágio mais desenvolvido, "[...] é a luz universal que modifica todas as outras cores econômicas e sociais" (LÖWY, 1998, p. 74).

Sendo assim, o modelo/concepção de UCM é utilizado pelos agentes sociais de decisão como um arquétipo com o qual se induz à competitividade internacional e visa-se garantir, entre outras questões: 1) que o trabalho tradicionalmente realizado nos países mais industrializados seja feito de forma qualificada e flexível também nos países considerados emergentes; 2) o fomento do mercado da mobilidade internacional; 3) a descaraterização progressiva da universidade como um bem público, tornando-a cada vez mais elitista e articulada aos interesses do mercado.

Do mesmo modo, compreendemos que o perfil de UCM para países que não compõem o eixo dinâmico do capital, como os da $\mathrm{ALeC}$, guarda suas especificidades, como a criação de centros/nichos de excelência, grupos e redes de pesquisa nacionais e internacionais, que, por sua vez, também estão articulados às demandas dos setores industrial e de serviços.

Há, certamente, movimentos de resistência e de problematização da lógica ora exposta, indo ao encontro de projetos que vislumbram outra perspectiva para a universidade latino-americana, mais referenciada na função social que historicamente as IES assumiram nestes países. Urge, pois, que as universidades, os sindicatos e os movimentos sociais se articulem, a fim de que possam “[...] apurar melhor e construir consensos de forma mais rigorosa sobre a internacionalização e as métricas que avaliam a internacionalização, o uso de rankings" (LEAL; LEHER; AZEVEDO, 2018, p. 8). Afinal, “[...] ter uma região do planeta em defesa da educação pública faz diferença" (LEAL; LEHER; AZEVEDO, 2018, p. 7). Tais questões, contudo, configuram objeto para outro necessário artigo. 


\section{REFERÊNCIAS}

ALTBACH, P. G.; BALÁN, J. World Class Worldwide: transforming research universities in Asia and Latin America. Baltimore: Johns Hopkins University Press, 2007.

ALTBACH, P.; SALMI, J. The road to academic excellence: the making of world-class research universities. Washington: The World Bank, 2011.

BALL, S. J. Profissionalismo, gerencialismo e performatividade. Cadernos de Pesquisa, [S. 1.], v. 35, n. 126, p. 539-564, set./dez. 2005.

BIANCHI, A. O desenvolvimento desigual e combinado: a construção do conceito. Esquerda on line, [S. 1.], 4 fev. 2013. Disponível em: https://bit.ly/2R8L7KU. Acesso em: 10 out. 2017.

CHESNAIS, F. A mundialização do capital. São Paulo: Xamã, 1996.

FAIRCLOUGH, N. Discurso e mudança social. Brasília: UnB, 2001.

FRIGOTTO, G. O enfoque da dialética materialista histórica na pesquisa educacional. In: FAZENDA, I. (Org.). Metodologia da pesquisa educacional. São Paulo: Cortez, 1991. p. 69-90.

HAZELKORN, E. Reflections on a decade of global rankings: what we've learned and outstanding issues. Beitraege zur Hochschulforschung, Munique, n. 2, p. 8-33, 2013.

LEAL, F. G.; LEHER, R; AZEVEDO, M. L. N. Perspectivas e desafios para a Educação Superior na ALeC: entrevista com Roberto Leher, Reitor da Universidade Federal do Rio de Janeiro, com comentários de Mário Luiz de Azevedo, da Universidade Estadual de Maringá. Arquivos Analíticos de Politicas Educativas, [S. 1.], v. 26, n. 166, p. 1-22, 2018.

LÖWY, M. A teoria do desenvolvimento desigual e combinado. Revista Outubro, [S. 1.], 1. ed., p. 73-80, 1998. Disponível em: https://bit.ly/2CinnPd. Acesso em: 21 nov. 2017.

MARGINSON, S. Dynamics of national and global competition in higher education. Higher Education, v. 52, n. 1, p. 1-39, 2006. Disponível em: https://bit.ly/2PnLSTa. Acesso em: 20 ago. 2017.

SADLAK, J.; CAI, L. N. (Eds.). The World-Class University as part of a new higher education paradigm: from institutional qualities to systemic excellence. Bucharest: Unesco-Cepes, 2009.

SALMI, J. The challenge of establishing World-Class Universities. Washington: World Bank, 2009.

SALMI, J. Atreverse a volar alto: una estrategia para desarrollar universidades de rango mundial en Chile. Pensamiento Educativo - Revista de Investigación Educacional Latinoamericana, [S. 1.], v. 50, n. 1, p. 1-30, 2013. 
SCHAWARTZMAN, S. Universidad y desarrolho em Latino America: experiencias exitosas de centros de investigación. Caracas: Iesalc/Unesco, 2008. Disponível em: https://bit.ly/2FLCbXQ. Acesso em: 15 dez. 2018.

THIENGO, L. C. Universidades de Classe Mundial e o consenso pela excelência: tendências e manifestações globais e locais. 2018. 366f. Tese (Doutorado em Educação). Programa de Pós-Graduação em Educação da Universidade Federal de Santa Catarina (UFSC), Florianópolis, 2018.

UNESCO INSTITUTE FOR STATISTICS - UNESCO - UIS. Human Resources in R\&D. UIS Fact Sheet, Montreal, no 35, p. 1-6, nov. 2015.

UNESCO INSTITUTE FOR STATISTICS - UNESCO - UIS. Education statistics. [S. 1.], 2016. Disponível em: https://bit.ly/2I247cA. Acesso em: 05 out. 2016.

Texto recebido em 08 de março de 2019. Texto aprovado em 27 de abril de 2019. 